\title{
OS AMIGOS DA BRANQUINHA: ENTRE A REPRESSÃO E A RESISTÊNCIA
}

\section{THE FRIENDS OF "BRANQUINHA" BETWEEN THE REPRESSION AND THE RESISTANCE}

\author{
Amilcar de Souza MARTINS*
}

Resumo: A partir da década de 30, com a emergência de Getúlio Vargas ao poder foi criado um projeto de idealização do trabalhador brasileiro, onde hábitos como o consumo de bebidas deveria ser controlado. No Pará esse projeto de disciplinarização do trabalhador ganhou força na interventoria de Magalhães Barata, que proibiu o consumo e comércio de aguardente, interferindo numa prática comum entre as camadas populares do Pará.

Palavras-chave: Controle. Resistência. Cachaça.

Abstract: From 1930,with the emergence of Getulio Vargas to power was created a project of idealization of Brazilian workers, where habits such as the consumption of drinks should be controlado.No For this project of disciplinarization of worker gained strength in interventoria Magalhães Barata, which forbade the consumption and trade of brandy interfering in a common practice among the popular classes.

Keywords: Control. Resitance. Cachaça

\section{Introdução}

O objetivo desse trabalho é tentar decifrar quais os interesses que levaram o Estado paraense a promover uma política de combate ao alcoolismo nas décadas de $30 \mathrm{e}$ 40, tendo como alvo principal os consumidores. Além disso, o trabalho pretende mostrar qual a postura dos diferentes sujeitos que se envolveram ou foram atingidos pelas medidas proibicionistas, bem como suas formas de controle e resistência.

Para adentrar num conjunto de relações constituintes do fazer-se de uma importante dimensão do cotidiano do espaço urbano belemita, serão utilizadas como fontes as notas policiais do Jornal A folha do Norte, uma vez que era um dos principais diários da época, pois produziu uma série de referências em relação aos sujeitos que foram sofreados de beber.

Sabe-se que as notas de jornais, nos possibilita apenas um conhecimento parcial sobre o assunto, o que não impede de fazer um criativo diálogo com as informações

\footnotetext{
* Pós-graduando em Linguagens e Saberes da Amazônia, Universidade Federal do Pará, Campus Universitário de Bragança-PA. Professor vinculado à Seduc-PA e ao Centro de Referência em Educação Ambiental Escola Bosque Professor Eidorfe Morreira. Email: peixe_martins@yahoo.com.br.
} 
trazidas à baila. Com esses noticiários, é factível apreender um universo de vivenciais entre distintos grupos sociais que, reivindicando interesses, direitos e perspectivas de mundo, colocaram em questionamento as atitudes do poder político local.

O assunto é deveras importante, na medida em que existem poucas informações sobre um universo que fazia parte do cotidiano de uma parcela significativa da população no período, pois inúmeros homens e mulheres se viam de certa forma ligados ao mundo do Álcool, sejam eles prostitutas, comerciantes, boêmios, delegados, guardas civis, trabalhadores, ou seja, diferentes sujeitos de uma sociedade que se pretendia disciplinar.

\section{A Formação do Estado disciplinador: Táticas de controle e o ideal de cidadão da política Varguista}

O movimento de 30 - que culminou com a nomeação de Getúlio Vargas para a presidência da república - abriu caminho para a edificação de um Estado cujas vigas mestras foram o autoritarismo, o nacionalismo, o anticomunismo e a criação de uma ideologia de trabalho de vertente conservadora, orientada para facilitar o avanço da economia de mercado na formação social brasileira.

Entre 1930 e 1945, o Governo Vargas adotou um conjunto de medidas destinadas a operar uma crescente limitação nos níveis de autonomia das classes trabalhadoras, objetivando afetar a dinâmica de vida dos segmentos sociais subalternos, tanto no âmbito público como privado, de modo a conformá-los aos padrões condizentes com os hábitos e valores prescritos e/ou tolerados pelos grupos privilegiados, no interior da ordem burguesa em questão.

Como parte das medidas supracitadas, podemos destacar a criação da Lei de sindicalização de 1931 (Decreto 19770), que trouxe os sindicatos e associações de classe para a esfera estatal, concorrendo para forjar uma estrutura sindical centralizada, voltada para coibir a ação de setores considerados subversivos no coração das organizações classistas, capazes de por em cheque a lógica da acumulação capitalista em expansão no território nacional.

Este instrumento legal, ao lado da legislação social de 1932 - garantidora de direitos como férias, aposentadoria, pensões, etc. - aparecem muitas vezes no discurso governista como se fossem presentes doados às classes trabalhadoras. 
Dessa maneira os agentes do Estado, e mais particularmente Vargas, são investidos no plano simbólico de poderes especiais, que os representam com capacidade para identificar e sanear as demandas do povo trabalhador, sem que este precisasse recorrer a nenhum tipo de instrumento de pressão, como greves e lockouts. A imagem de Vargas como chefe benevolente e paternal fora zelosa e compassadamente edificada como recurso de cooptação dos trabalhadores, de modo a incitá-los a comportarem-se nos marcos da ordem oficial dita revolucionária.

O avanço do êxito da política varguista, no período entre 1930 e 1935, se explica, em boa medida, pela forma como em seu interior se articulou competentemente o uso de forças repressivas e persuasivas, integradoras dos planos físico, econômico e simbólico, indispensáveis para sedimentar os interesses dos grupos empresariais e governamentais, então ideológica e politicamente hegemônicos.

Neste universo ocupou papel de relevo toda uma série de imagens e representações enaltecedoras do trabalhador, idealizado como um bom cidadão e chefe de família, provedor do lar e cultivador dos bons costumes, a partir das quais se irradiaram de práxis sintonizadas com a visão de nação, cidadania e liberdade dos grupos encastelados no poder.

São estas imagens e representações que vão alimentar, de certa forma, o cerne dos discursos encetados pelos guardiões dos interesses dos grupos há pouco mencionados, destinados a combater o consumo de álcool e fumo, a prostituição, o ócio e a jogatina. Estas condutas passam a ser, nesse contexto, fortemente estigmatizadas, rotuladas como um mal à nação, como desencadeadoras de comportamentos imorais e degradantes, não condizentes com aquele esperado do trabalhador-cidadão, idealizado pela propaganda estatal.

Para Ângela de Castro Gomes, a ideologia do trabalho, no período em apreciação, investia à labuta de atributos dignificadores e moralizadores indispensáveis à formação do cidadão-trabalhador, imprescindíveis à composição de um povo integrado por pessoas solidárias e obedientes às autoridades instituídas. Em sua opinião,

(...) a marca dessa solidariedade era dada por um princípio jurídicoeconômico e também moral. O povo eram os que trabalhavam, por distinção aos que estavam fora - os desempregados, os mendigos, os criminosos ou os subversivos, em suma, os marginais (...). O comprometimento pelo trabalho entendido em lato sensu - significa ganhar identidade política, isto é, passar de um modo de ser para outro (GOMES, 2005, p. 231).

Para Salgado Filho, Ministro do Trabalho entre 1932 e 1934, o trabalho funcionava como uma espécie de remédio para o mal da ociosidade, do álcool, da 
boemia, além de ser uma possibilidade de crescimento pessoal e de valorização do cidadão.

Assim, o controle e o combate à figura do bebedor vai se contornando aos poucos, apoiado inclusive em argumentos de caráter cientificista, direcionados a promover o controle de maus hábitos, prevenir e/ou curar doenças. A historiadora Maria Izilda Mattos, referindo-se ao discurso médico-científico, norteador da luta antialcoólica, entre os anos 1891 e 1940, afirma:

\begin{abstract}
Nesse processo os médicos assumiram vários papeis: como higienistas e sanitaristas combateram o alcoolismo com campanhas e ações diversificadas; como legistas, discutiram as responsabilidades dos alcoólatras e a relação álcool-violência-crime; também nos hospitais e manicômios procuraram aperfeiçoar tratamento para os alcoólatras, além de lutar por instituições especiais para abrigá-los (...). Nesse quadro, o papel dos médicos e higienistas era de importância vital, já que consideravam o país na sua vocação para o progresso e para a civilização (MATOS,2001, p. 27)
\end{abstract}

O pensamento médico-científico em questão chega mesmo a enquadrar o alcoolismo como uma anomalia, doença de alto grau de periculosidade, merecedora de todos os cuidados, pois:

(...) tornava os homens embrutecidos, selvagens, feras, primitivos, trazendo à tona todos os seus instintos bárbaros, irracionais e bestiais. Sua razão passava a ser obtusa, com falta de raciocínio, ao mesmo tempo despertando "certos instintos" brutais no homem, estimulando a ferocidade, as paixões os ciúmes e, nessas condições, facilitando o crime (...) (MATOS, 2001, p. 69)

Os argumentos médico-científicos, no Brasil dos anos 30, servem muitas vezes para embasar estratégias de políticas públicas normatizadoras, que emergem para fazer frente a situações decorrentes do crescimento desordenado e complexo de muitas cidades. No Pará, a situação não foi diferente, ainda que seja preciso considerar as especificidades das orientações nacionais sobre o trabalhador, assim como práticas sociais instituídas pelo poder público, os jornais de Belém, como "A Folha do Norte", no período de 1931 a 1935, reforçam esse pensamento, estigmatizando os consumidores de álcool como desordeiros, imorais e viciados, que deveriam ser corrigidos no xadrez. A esse respeito noticiou o referido jornal:

Outra vez com a cara amarrotada e a boca amargando que nem fel, amanheceu na central de polícia o carregador Raymundo Vieira dos Santos morador da rua Sto. Amaro.

O Mundico viciou-se demasiadamente na cachaça, a ponto de não passar um dia só sem tomar umas cipoadas.

A noite de anteontem, a esponja dobrou a dose e ficou peor que peru de crhista caída, sendo conduzido ao casarão da rua Sto Antônio 1 .

\title{
A cruzada Baratista anti-cachaça e os Amigos Branquinha
}


No Estado do Pará, esta política disciplinadora, encontrou terreno sob a forte influência da interventoria de Magalhães Barata, inaugurada a partir de 12 de novembro de 1930. Como representante do governo revolucionário, este governante enfeixou em suas mãos uma série de poderes discricionários, permitindo-lhes executar ações voltadas ao controle da vida dos cidadãos, chegando a ponto de deflagrar diligências destinadas a perseguir os consumidores de bebidas alcoólicas, principalmente os amantes do "precioso líquido branco": a cachacinha.

No discurso da interventoria baratista, o alcoolismo aparece intimamente associado à boemia, à malandragem, à prostituição e à indolência, posturas recriminadas por serem incompatíveis com as normas do bem-viver de uma sociedade requerida como civilizada. Assim, a luta antialcoólica vai ganhando contornos, com o fechamento de bares, quiosques, tabernas e botequins, além de multas para os infratores da portaria de número 116, que proibia a venda de cachaça, sancionada, em dezembro de 1930.

A medida "moralista" de Barata, de proibir o consumo de cachaça sob a justificativa de combate ao alcoolismo, restringia a venda da branquinha, permitindo-a apenas para atender demandas industriais e farmacêuticas.

Foi comum uma série de violências utilizadas pelo governo de Magalhães Barata contra os bebedores de Belém, no período situado entre 1930 e 1935. Os "amigos da branquinha", na realidade compuseram o quadro dos atores principais perseguidos pela polícia baratista. Alguns destes chegaram a se transformar em personagens folclóricas, que ganharam notabilidade nas páginas policiais da Folha do Norte por serem apreciadores da cachaça, bebida proibida de ser consumida e comercializada pela instrução 116, como mencionamos anteriormente.

Dentro do universo do pessoal da pinga, dois personagens destacam-se, segundo as notas policiais do periódico "A Folha do Norte" por serem freqüentadores assíduos de bares, botequins e do xadrez da Central de Polícia. São eles: Maria Rodrigues Carvalho, vulgarmente conhecida como Maria do Combate, e Manuel Ferreira da Costa, conhecido pela alcunha de Camelo, dada a sua capacidade de armazenar cachaça.

Maria Rodrigues Carvalho várias vezes fora alvo da ação policial, envolvida comumente em casos de embriaguez e desordem. Em artigo publicado no jornal pesquisado, em 21 de maio de 1933, noticia-se:

Já se tornou uma figura popular em Belém, pelas suas constantes bebedeiras, a mundana mais conhecida como Maria do Combate.

Em todos os postos policiaes da cidade seu nome figura uma dezena de vezes, sempre pelo mesmo motivo - embriaguez e escândalo. 
Uma vez alcoolizada, a infeliz profere em via pública, em alta voz, os nomes mais indecorosos, obrigando as famílias fechar suas portas.

Ultimamente Maria do Combate adquiriu um hábito, que importuna muito mais que sua própria cachaça.

Presa, bate com os tamancos no xadrez, produzindo um barulho infernal, que incomoda os outros detidos e as autoridades de permanência.

Hontem por exemplo, a perigosa mundana quase poê todo mundo louco na central, com a pancadaria nas portas da prisão ${ }^{2}$.

Manuel Ferreira da Costa, assim como Maria do Combate, tinha também "cadeira cativa" na Central de Polícia, por desrespeitar frequentemente a chamada Lei Seca.

Quando íamos nos retirar hontem a tarde da Central de Polícia, deu entrada alli - Manuel Ferreira da Costa, parahybano, pardo, solteiro, sem profissão nem residência muito conhecido da polícia.

Manuel é um desses indivíduos que bebe pra esquecer as magoas.

Já tendo muitas entradas na Central acostumou-se a ir de tal maneira que não lhe causa menor contrariedade o passar a noite num dos confortáveis compartimentos.

O comissário Pingarilho é talvez, o que já tem tido oportunidade de mandar prende-lo o maior número de vezes. Por isso este já o distingue dos outros colegas $^{3}$.

Homens e mulheres como Manuel Ferreira da Costa e Maria Rodrigues Carvalho representavam uma ameaça para o projeto de saneamento moral da sociedade belenense, ao portarem-se em desalinho com os costumes projetados pelos membros da boa sociedade. São desempregados, bêbados, arruaceiros, que usam a bebida ao arrepio da legislação. São elementos alijados do mundo do trabalho, excluídos da sociedade, não cidadãos, segundo as regras forjadas pelos integrantes do Estado getulista.

Segundo as orientações da política do trabalho propostas pelo governo federal, abstendo-se do álcool o trabalhador economizaria suas energias, aumentando consideravelmente sua capacidade produtiva. A bebida, assim como o jogo e o lazer exacerbado, concorreria para promover um desperdício de energia, acarretando uma degradação moral e física do trabalhador, ameaçando a disciplinada e moral pátria.

Não por acaso a figura autoritária de Magalhães Barata aparece frequentemente nos discursos oficiais e/ou oficiosos como uma figura cercada de atributos de honestidade e honradez cuja intenção era promover o "saneamento" do Estado do Pará ${ }^{4}$. Esses "atributos" credenciavam este governante a apresentar-se como o guia dos integrantes da sociedade paraense, cujas ações estariam afinadas com as aspirações da grande maioria do povo.

Esta vertente de direcionamento político-ideológico moldava a sensibilidade de parte da sociedade belemita, levando-a a se identificar com o interventor de tal maneira, em algumas situações, a ponto de, muitas das vezes, atuar como fiscal do governo. No caso da Lei Seca encontramos um interessante relato que confirma esse posicionamento:

Os moradores do Guamá pedem por nosso intermédio, a atenção da polícia para o abuso de certos taverneiros, possuindo grande "Stock" de cachaça, embora conservando-o fora das suas mercearias, fornecem essa bebida a 
casas particulares e a venda a certos indivíduos, com evidente desrespeito a Portaria do Sr. Chefe de Polícia ${ }^{5}$.

Além do apoio de alguns membros da sociedade à repressão em relação aos bebedores, a polícia possuía um papel preponderante, pois a partir de algumas batidas policiais, tentava impedir as ações dos contrabandistas de cachaça, que tentavam de todas as formas comercializar o líquido branco (cachaça). Nessa tentativa de coibir o comércio ilegal de cachaça, encontramos vários bares, tabernas, botequins que foram multados e fechados por desrespeitarem a Lei contra a branquinha:

O comissário Costa e Lima, do Posto de Polícia de São Braz ontem à noite, deu uma batida naquella zona, a procura dos infractores da "lei seca", conseguindo pegar na Padaria Trunfo a travessa José Bonifácio $\mathrm{n}^{\mathbf{o}} 6$ de propriedade de A. B. Gonçalves e Simões, 2 barris de cachaça, na mercearia Floresta de São Francisco, de Argemiro Mendonça, situada a mesma travessa letra B, uma garrafa do precioso líquido, no Quiosque denominado Esportivo no largo de São Braz, de propriedade de Alípio e Fonseca também uma garrafa, na Casa Gouvêa, a travessa José Bonifácio, esquina da rua dos Mundurucus, de propriedade de Manuel Rodrigues uma garrafa da "branquinha em cada uma".

O comissário Costa e Lima, depois de aprehender barris e garrafas, estimou os infractores e entrarem todos com a multa de $100 \$ 000$ cada um $^{6}$.

Essa fiscalização na luta contra o alcoolismo, em grande parte era prejudicada pela ação dos consumidores, taberneiros que várias vezes usaram diversos mecanismos para burlar a Lei Seca, pois indubitavelmente a cachaça fazia parte do cotidiano cultural e alimentar do povo paraense.

Dentre as estratégias utilizadas evidenciou-se casos como o da prisão da dupla Manuel Raimundo e Francisco que, segundo nota policial, foram denunciados por "traficarem cachaça", em latões de querosene, na canoa Aripis, oriunda do município de Maracanã:

Às 7:10 da noite, davam entrada presos na estação de polícia, Manuel Raimundo, pardo de 21 anos, solteiro, lavrador e Francisco Bahia, paraense, branco de 28 anos, encarregados da canoa "Aripis", precedente de Maracanã, ancorada no igarapé das Almas. A recebedoria desta denúncia que uma canoa trazia para Belém regular contrabando de cachaça, e à tardinha empregados naquela repartição deram uma busca na embarcação, encontrando 15 latas de kerozene, cheios de cachaça $(. . .)^{7}$.

Sem contar aqueles que misturavam o "precioso líquido branco" em recipientes contendo suco de frutas ou até mesmo leite de gado, na tentativa de driblar a repressão dos comissários de polícia, como fora o caso da prisão dos leiteiros Crhistiano Pinto e Fulgêncio pereira andrade:

o comissário de batista campos, porque o bairro é muito socegado, passa muito tempo a descansar; mas quando começar a agir é um deus nos acuda! 


\begin{abstract}
hontem, a noite, os agentes tiveram um trabalhozinho. trata-se de um contrabando de cachaça.

o portuguez cristiano pinto, leiteiro de 20 annos, solteiro, residente a rua timbiras, $\mathrm{s} / \mathrm{n}^{\mathrm{o}}$, auxiliado por fulgêncio pereira andrade paraense, pardo, 19 annos, solteiro, sem profissão, residente a mesma rua, entendeu de contrabandear tão apreciada dos farristas.

como é leiteiro de profissão, supoz que enganaria a vigilância da polícia, utilizando-se para isso, dos recipientes em que conduz o leite a freguesia. os agentes de polícia, porém, desconfiaram e convidaram o conductor de cachaça a comparecer ao posto de batista campos, para onde levaram também contrabando.

effectivamente, os recipientes continham, em vez de leite, a perniciosa bebida. e o portuguez crhistiano pinto e o seu auxiliar fulgêncio pereira de andrade, afim de não venderem gato por lebre, ficaram detidos no xadrez do posto de batista campos, onde foi inaugurado inquérito a respeito ${ }^{8}$.
\end{abstract}

Por derradeiro, fica nítido que apesar do Estado fomentar a repressão em torno do consumo de cachaça, considerada um vício que degenerava o cidadão paraense, muitos sujeitos sociais mantiveram seus hábito de consumi-la, criando uma série de formas de resistência aos mecanismos de controle do governo em tela.

\title{
Considerações Finais
}

A partir desse estudo feito acerca da repressão e controle do Estado sobre as classes trabalhadoras, ficou nítido que durante décadas a bebida ocupou um espaço importante nesse projeto, haja vista que embriagar-se representava um atentado ao projeto de ideologia burguesa de disciplinas práticas e condutas das camadas populares.

Por conta disso, os espaços de divertimento frequentados pela boemia e pelos trabalhadores deveriam, frequentemente, ser objeto de inspeção por parte das autoridades, a fim de corrigir as condutas desviantes que ameaçavam a ordem e a moral de uma sociedade empenhada em civilizar-se.

Para fazer valer a ideologia trabalhista e atingir o progresso da civilização, os interventores, em especial, Magalhães, estabeleceu diversos mecanismos de proibição que prejudicaram diretamente os setores populares paraenses, que se viam tolhidos de degustar uma bebida barata e prazerosa como a cachaça, que fazia parte do seu cotidiano alimentar, costumes, tradições e de seus modos de viver: a diversão, o lazer e o entretenimento.

A presença efetiva e ativa desses setores no palco das tensas relações geradas em função do consumo da "branquinha" (cachaça) produziu enfrentamentos sociais. No decorrer do texto foi possível visualizar um conjunto de resistências desencadeadas 
pelos diferentes consumidores e vendedores de bebida, objetivando manterem sua rotina boêmia.

Por fim, ressalta-se que com o aprofundamento do estudo verificou-se que não só a bebida objeto de intervenção, mas também uma série de outras drogas que comumente eram usadas pelos cidadãos tais como o lança-perfume, o éter e a popular diamba (maconha). No entanto essa abordagem será em outro momento.

\section{Referências}

Ardil Totalitário - Imaginário Político no Brasil dos Anos 30. $1^{\text {a }}$ ed. Vol. 1. Belo Horizonte/Rio de Janeiro: Editora da UFMG/Editora da UFRJ, 1997.

BEZERRA NETO, José Maia \& ALVES JÚNIOR, José (Orgs.) Pontos da história do Pará. Vol. 02. Belém: Paka-tatu, 2000

BRETAS, Marcos L. Ordem na Cidade - o exercício da autoridade policial no Rio de Janeiro: 1907-1930. Rio de Janeiro: Rocco, 1997.

CASCUDO, Luís da Câmara. Prelúdio da cachaça: Etnografia, história e sociologia da aguardente no Brasil. Rio de Janeiro, 2005. (Coleção Canavieira)

CHALOUB, Sidney. Trabalho, Lar e Botequim: cotidiano dos trabalhadores do Rio de Janeiro. 2 ed. Campinas: Editora da Unicamp, 2001.

COIMBRA, Creso. A Revolução de 30 no Pará - Análise, crítica e interpretação da história. $1^{\circ}$ ed. Coleção História do Pará, Série "Arthur Vianna", Conselho Estadual de Cultura, Belém-PA, 1981.

GOMES, Ângela. A invenção do trabalhismo. $3^{\mathrm{a}}$ edição. Rio de Janeiro, IUPERJ, 2005.

MATOS, Maria Izilda Santos de. Meu lar é o botequim. São Paulo, Nacional, 2000.

RAGO, Luiza Margareth. Do cabaré ao lar: a utopia da cidade disciplinar - Brasil 1890 -1930. Rio de Janeiro: Ed. Paz e Terra, 1997.

SHOWALTER, Elaine. Anarquia Sexual: Sexo e Cultura no Fin-de-Siècle. Rio de Janeiro, Rocco, 1990.

VENANCIO, Renato Pinto; CARNEIRO, Henrique. Álcool e drogas na história do Brasil. São Paulo: Alameda. 2005.

\section{Notas:}

${ }^{1}$ A Folha do Norte, Ed. de 13 de outubro de 1932. 
${ }^{2}$ A Folha do Norte, Ed. de 21 de maio de 1933.

${ }^{3}$ A Folha do Norte, Ed. 13 de setembro de 1931.

${ }^{4}$ Em entrevista dada ao jornal carioca Correio da Manhã, no dia 10 de fevereiro de 1931, Magalhães Barata ressalta a necessidade de guiar o Estado ao desenvolvimento, entretanto para isso era preciso haver o saneamento do Estado.

${ }^{5}$ Folha do Norte, Ed. 10 de janeiro de 1931.

${ }^{6}$ Folha do Norte, Ed. de 3 de janeiro de 1931.

${ }^{7}$ Folha do Norte, ed 20 de janeiro de 1931.

${ }^{8}$ Folha do Norte, Ed. de 27 de novembro de 1931.

[Recebido: 20 jul. 2014 / Aceito: 17 set. 2014] 